\title{
DEVELOPMENT OF STORMWATER DRAINAGE NETWORK MODEL: MODRAIN CODE
}

\section{IFY L. NWAOGAZIE AND ITOLIMA OLOGHADIEN}

(Received 10, October 2011; Revision Accepted 14, February 2012)

\begin{abstract}
The development of a storm drainage design and simulation model called MODRAIN is presented. The MODRAIN code is written in visual basic language, version 6.0 (VBL) as well as Fortran IV. It consists of two parts; the MAIN program and a subroutine, SDRAIN. In the MAIN program all the input data are entered on screen for VBL. The MAIN program simulates the catchment runoff while the subroutine, SDRAIN sizes the drain by computing depth and width values of each channel cross-section from simulated runoffs. The program was then validated against the prototype network cited in literature. The error range for the manually computed (textbook solution) and simulated depth and width values of drains as per cross sectional areas is between 0.0 and $18.4 \%$. The modrain program was further applied to the design and assessment of existing drainage network of University of Port Harcourt Permanent site (Unipark) and thus, proved to be a reliable engineering design tool.
\end{abstract}

\section{INTRODUCTION}

Drainage is a high priority urban service and the associated problems are increasingly becoming a concern due to rapid urbanization and global climate change impacts. Consequently, a channel whose geometry minimizes the cost of excavation and linning is often desired. Therefore, for a given discharge, slope, and roughness, the designer aims to minimize the cross-sectional area, in order to reduce construction costs (Henderson, 1966). It has been shown that the most "efficient" crosssectional shape is one that the wetted perimeter is also minimum (Streeter and Wylie, 1981; Nwaogazie and Uba , 2001).

Based on the existing literature review on the subject, one may infer that the progress in urban stormwater drainage modeling has not been uniform in time or across different countries or regions. Furthermore, the various models may give different solutions to the same problems; thus communities that are experiencing urbanization may develop their own urban storm drainage model and local drainage design practice (Viessman and Lewis, 2008). The objective of this paper is to present the development of a drainage network analysis model (MODRAIN) using the basic approach: Rational formula method, rainfall IntensityDuration-Frequency (IDF) versus time of concentration model and best hydraulic section for sizing of drains. Practical utility of MODRAIN include: assessment of performance of existing or proposed drainage system for flood mitigation, stormwater management and development of local drainage practice.

\section{MATHEMATICAL DEVELOPMENT}

The application of the concept of "best or most efficient hydraulic section" for gutter and culvert is necessary for cost reduction during actual construction (Nwaogazie and Uba, 2001). By the definition of hydraulic radius, $R$ the minimization of wetted perimeter may be taken as the problem of maximization of $R$. Thus, a channel of maximum $R$ not only results in

Ify L. Nwaogazie, Department of Civil \& Environmental Engineering, University of Port Harcourt, Port Harcourt, Nigeria.

Itolima Ologhadien, Department of Civil Engineering, University of Science and Technology, PMB 5080, Nkpolu Port Harcourt, Nigeria. 
optimum hydraulic design but also tends towards a section of minimum cost. The basic formula for best hydraulic section for trapezoidal or rectangular cross-section (see Fig 1) may be derived as follows:

For the trapezoidal section, hydraulic radius is given as:

$$
R=\frac{A}{P}=\frac{b y+z y^{2}}{b+2 y\left(1+z^{2}\right)^{1 / 2}}
$$

and

$$
P=\left(\frac{A}{y}-z y\right)+2 y \sqrt{1+z^{2}}
$$

Where;

$y=$ Hydraulic depth (m);

$\mathrm{R}=$ Hydraulic radius $(\mathrm{m})$;

$A=$ Cross-sectional area $\left(\mathrm{m}^{2}\right)$;

$z=$ Channel side slope (see Fig 1$)$;

$\mathrm{b}=$ Bottom width $(\mathrm{m}) . ;$ and

$\mathrm{P}=$ Wetted perimeter $(\mathrm{m})$, which assumes a minimum value when $\frac{d P}{d y}=0$.

Differentiating Equation (2) with respect to y, we have:

$$
\frac{d P}{d y}=\left(\frac{-A}{y^{2}}-z\right)+2 \sqrt{1+z^{2}}=0
$$

Solving for A, we have:

$$
A=y^{2}\left(2 \sqrt{1+z^{2}}-z\right)
$$

Equating Equation (4) with the area of trapezoidal channel (see numerator of Eq.1) gives the value of channel width as:

$\mathrm{b}=2 \mathrm{y}\left(\sqrt{z^{2}+1}-z\right)$

Substituting Equation (5) into Equation (1), gives an efficient maximum hydraulic radius, $R_{\max }$ as:

$\mathrm{R}_{\max }=\frac{y}{2}$

For uniform flow in a channel or prismatic section, Chezy-Manning's equation may be written as:

$\mathrm{Q}_{\mathrm{p}}=\frac{1}{n} A R^{2 / 3} S_{o}^{1 / 2}$

Where $n$ is Manning's roughness coefficient; $S_{0}$ is normal channel slope; $Q_{p}$ is peak discharge or flow rate; and other terms are as previously defined. 


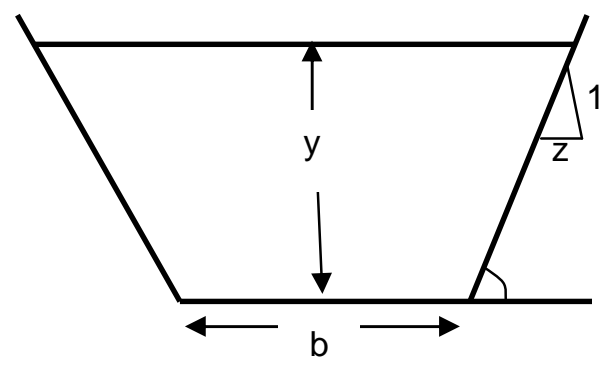

Fig. 1: Sketch of optimum trapezoidal section

For the depth of flow y, we substitute Equations (5) and (6) into Equation (7), which yields:

$y=\left[\frac{1.587 n Q_{p}}{\left(2 \sqrt{1+z^{2}}-z\right) S_{o}^{1 / 2}}\right]^{3 / 8}$

Equations (5) and (8) provide the hydraulic design models, while Equations (9)-(12) give the hydrologic aspects of runoff computation. The estimate of time required for runoff to travel from the most remote part of catchment to point of interest is given as (Agunwamba, 2001):

i) $\quad t_{c}=0.01947 \mathrm{~L}^{0.77} \mathrm{~S}^{-0.5}$

Where $t_{c}$ is time of concentration, $L$ is length of channel $(m)$; and $S$ is average catchment slope $(\mathrm{m} / \mathrm{m})$.

ii) For IDF rainfall intensity-duration computation, we have the quotient model of the type (Nwaogazie and Duru, 2002; Nwaogazie and Nwadike, 2010):

$I=a_{0} /\left(t_{c}+a_{1}\right)$

Where $\mathrm{I}$ is rainfall intensity $(\mathrm{mm} / \mathrm{hr}) ; \mathrm{t}_{\mathrm{c}}$ is duration, in minutes (same as time of concentration); and $a_{0}, a_{1}$ are regional constants. The constants $a_{0}$, and $a_{1}$ are transferred to the MODRAIN program as COEF1 and COEF2, respectively, after Equation (9) is evaluated with field data.

iii) The computation of peak runoff, $Q_{p}$ into the drain, we adopt the Rational formula:

$$
Q_{p}=C l A_{1} / 360
$$

where $Q_{p}$ is the peak runoff rate $\left(\mathrm{m}^{3} / \mathrm{sec}\right)$; $C$ is the runoff coefficient and $A_{1}$ is catchment area (ha). And $I$ is the design rainfall intensity from Equation (10).

iv) Velocity of flow, $v$ is given by:

$$
\mathrm{v}=\frac{1}{n} R^{2 / 3} S_{o}{ }^{1 / 2}
$$

Where the terms are as previously defined. 
3. COMPUTER AIDED DRAINAGE NETWORK SIMULATION

\subsection{Modrain Program Development}

MODRAIN computer code is written in

Visual Basic Language, version 6.0 and it consists of two parts; the MAIN program and a subroutine, SDRAIN. In the MAIN program, all the input data are entered on the screen. Estimate of overland flow or catchment runoff for all drains are equally made in the main program. The sequence of computation begins with the estimate of time of concentration, $t_{c}$ using Eq. (9), then the rainfall intensity via the evaluation of Equation (10) and thereafter, the computation of runoff flow into the drain, using Equation (11).

The subroutine SDRAIN sizes the drain by way of computing depth and width values of each channel cross-section. However, the choice of rectangular or trapezoidal section is made before hand via input data, before the subroutine SDRAIN is called. The velocity $v$ for the designed drain is computed and checked if the velocity limits $v \leq 1.0$ and $v \geq 3.0$ are satisfied to avoid siltation or erosion, respectively.

If the velocity value is less then $1.0 \mathrm{~m} / \mathrm{s}$, an upgrade of the estimated longitudinal slope, $S_{o}$ is made by a given percent. This is to avoid siltation in the drain. This slope upgrade is repeated many times as necessary and velocity, $v$ is correspondingly computed and checked until $v \geq 1.0 \mathrm{~m} / \mathrm{s}$. Similarly, if velocity, $v$ is greater than $3.0 \mathrm{~m} / \mathrm{s}$, then a reduction of slope, $S_{0}$ is made to avoid erosion. In each cycle of slope reduction by a given percent, velocity is recomputed and compared with set limits. And it is terminated once $v$ is $\leq 3.0$

Once all the drains have been sized by the subroutine, SDRAIN, then the simulated results per drain are printed out and program is terminated. The flow chart (Fig.2). shows the development of MODRAIN, the order in which the computations are made in the code.

\subsection{Input Data Structure}

The input data entry requirement, and the sequence of operations necessary to run the MODRAIN program are:

i). On the Main Menu, Click the Drain Analysis Dialogue box, twice, to load the program.

ii). Click "OK" on the user Login Menu;

iii). Click "Compute" to compute Network and Display Results to screen; and

iv). Click "File" to compute Network and Write Results to File

The user decides between (iii) and (iv) above. An example of input data format on the dialogue box is illustrated in the model verification example problem in Section 3.3. 


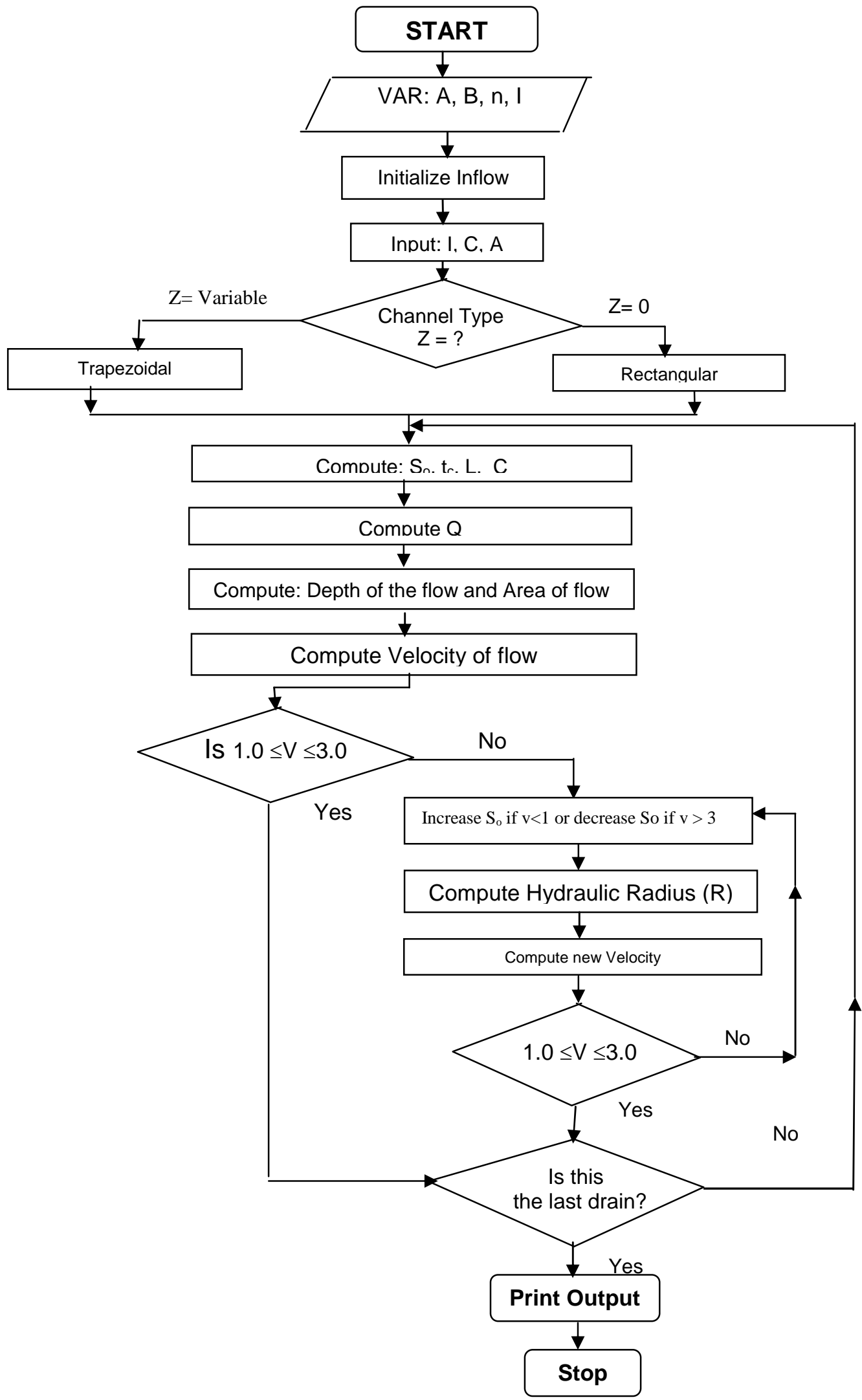

Figure 2: Flow Chart for Main Program 
3.3 Example Problem for Model Verification

area, residential, non-residential areas, Parks and cemeteries, and Farm land with corresponding runoff coefficients, C. The broken lines with arrow heads indicate flow directions in the drainage network while the distance inbetween two node numbers indicates length of a drain in metres. At node 12, drainage network discharges into a stream.

The input data for the example problem are as presented in Table 1, while in Table 2 the computer simulated results are compared and contrasted with the manually computed results in Agunwamba (2001). Likewise, the drain capacities $\left(\mathrm{m}^{3} / \mathrm{s}\right)$ for the 13 No. drains for both simulated and manually computed values are plotted (see Fig. 4) for sake of comparison.

Table 1: Input Data for Example problem 1

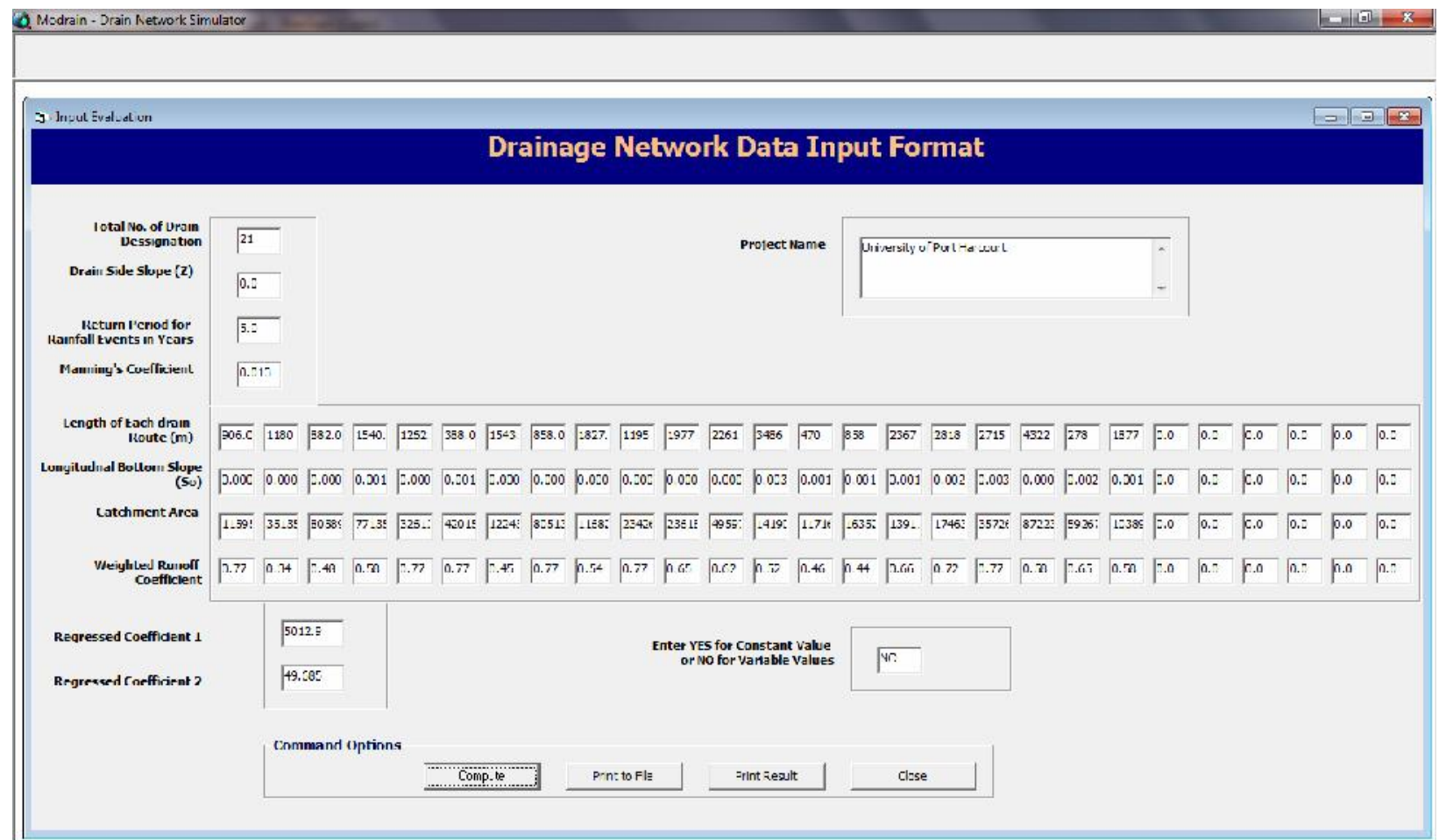




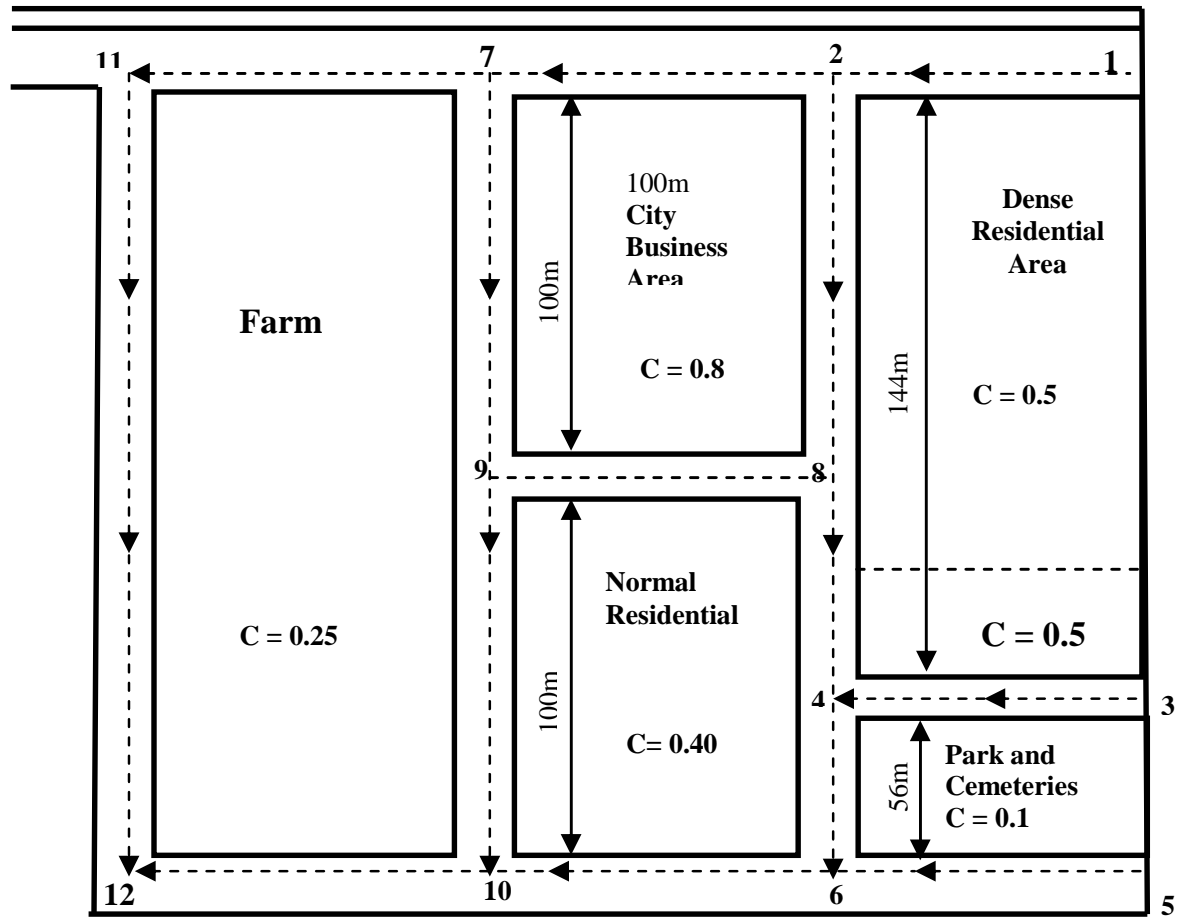

Fig. 3: Drainage Layout in Agunwamba (2001)

Table 2: Results of Model Verification

\begin{tabular}{|c|c|c|c|c|c|c|c|}
\hline \multirow[t]{2}{*}{$\mathbf{S} / \mathbf{N}$} & \multicolumn{3}{|c|}{ Computer Simulated Results } & \multicolumn{3}{|c|}{ Manually Computed Results } & \multirow{2}{*}{$\begin{array}{l}\% \text { Error } \\
\underline{\left(\mathbf{A}_{2}-\mathbf{A}_{1}\right) \times 100} \\
\mathbf{A}_{2}\end{array}$} \\
\hline & $\begin{array}{l}\text { Depth } \\
\text { (y) } \\
\text { (m) }\end{array}$ & $\begin{array}{l}\text { Width } \\
\text { (b) } \\
\text { (m) }\end{array}$ & $\begin{array}{l}\text { Area }\left(A_{1}\right) \\
\left(m^{2}\right)\end{array}$ & $\begin{array}{l}\text { Depth } \\
\text { (y) } \\
\text { (m) }\end{array}$ & $\begin{array}{l}\text { Width } \\
\text { (b) } \\
\text { (m) }\end{array}$ & $\begin{array}{l}\text { Area }\left(A_{2}\right) \\
\left(m^{2}\right)\end{array}$ & \\
\hline & 1 & 2 & 3 & 4 & 5 & 6 & 7 \\
\hline 1 & 0.1714 & 0.2958 & 0.0507 & 0.1713 & 0.2928 & 0.05016 & -1.08 \\
\hline 2 & 0.3718 & 0.6935 & 0.2578 & 0.3951 & 0.7402 & 0.29245 & 11.85 \\
\hline 3 & 0.2909 & 0.5318 & 0.1547 & 0.2909 & 0.5318 & 0.1547 & 0.0 \\
\hline 4 & 0.3921 & 0.7342 & 0.2879 & 0.3921 & 0.7342 & 0.2879 & 0.0 \\
\hline 5 & 0.1714 & 0.2928 & 0.05019 & 0.1714 & 0.2928 & 0.05019 & 0.0 \\
\hline 6 & 0.3474 & 0.6448 & 0.2240 & 0.3833 & 0.7165 & 0.27463 & 18.44 \\
\hline 7 & 0.1817 & 0.3133 & 0.05693 & 0.1827 & 0.3160 & 0.05773 & 1.39 \\
\hline 8 & 0.3890 & 0.7280 & 0.2832 & 0.412 & 0.774 & 0.31889 & 11.19 \\
\hline 9 & 0.1637 & 0.2770 & 0.04534 & 0.1644 & 0.2788 & 0.04583 & 1.07 \\
\hline 10 & 0.3975 & 0.7451 & 0.29618 & 0.4294 & 0.8089 & 0.34734 & 14.73 \\
\hline 11 & 0.3717 & 0.6934 & 0.25774 & 0.3947 & 0.7394 & 0.29184 & 11.68 \\
\hline 12 & 0.1753 & 0.30064 & 0.05270 & 0.1753 & 0.3006 & 0.05270 & 0.0 \\
\hline 13 & 0.2566 & 0.4633 & 0.1189 & 0.2614 & 0.4729 & 0.1236 & -5.3 \\
\hline
\end{tabular}




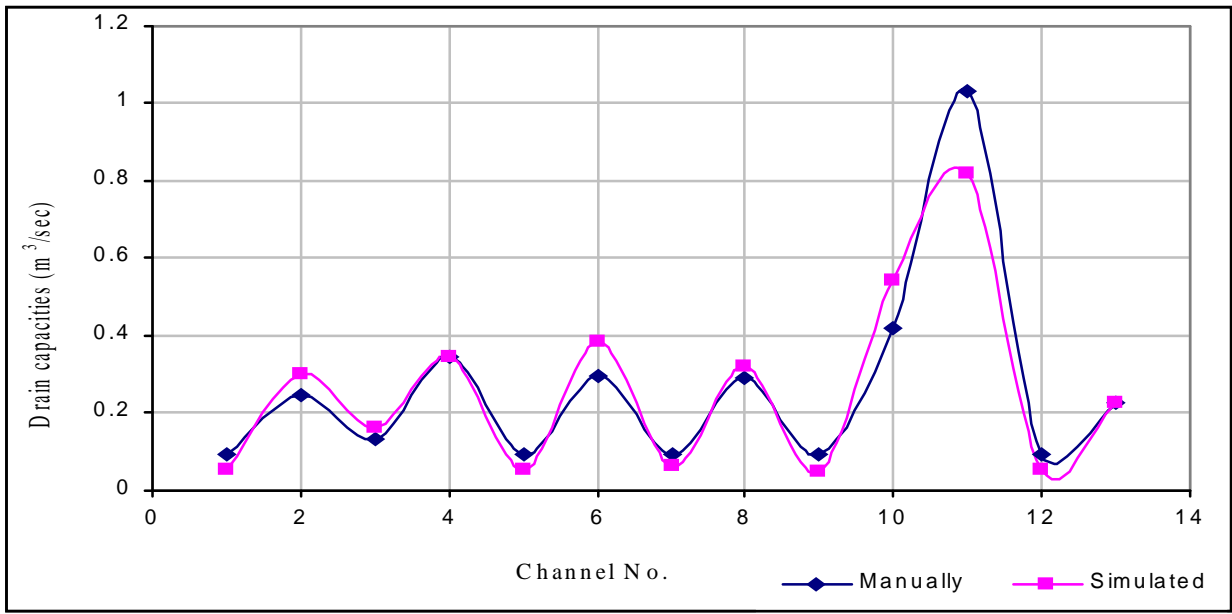

Fig. 4: Comparison of simulated with manually Computed Drain Capacity

\section{APPLICATION OF MODRAIN TO UNIPARK DRAINAGE NETWORK}

The University of Port Harcourt Permanent Site (Unipark catchment) is divided into eight subcatchments with areas $A_{1}$ to $A_{8}$. The degree of urbanization in each sub-catchment is represented by the runoff coefficient. The rainfall is assumed to be distributed uniformly over the entire catchment. The directly connected paved areas are mainly streets. The additional paved areas are the roofed areas, parks, mini-stadium and so on. The input data for modrain code are as presented in Table 3 , while the simulated results are presented in Table 4, respectively. Results in both Tables 3 and 4 are that of Fortran IV code.

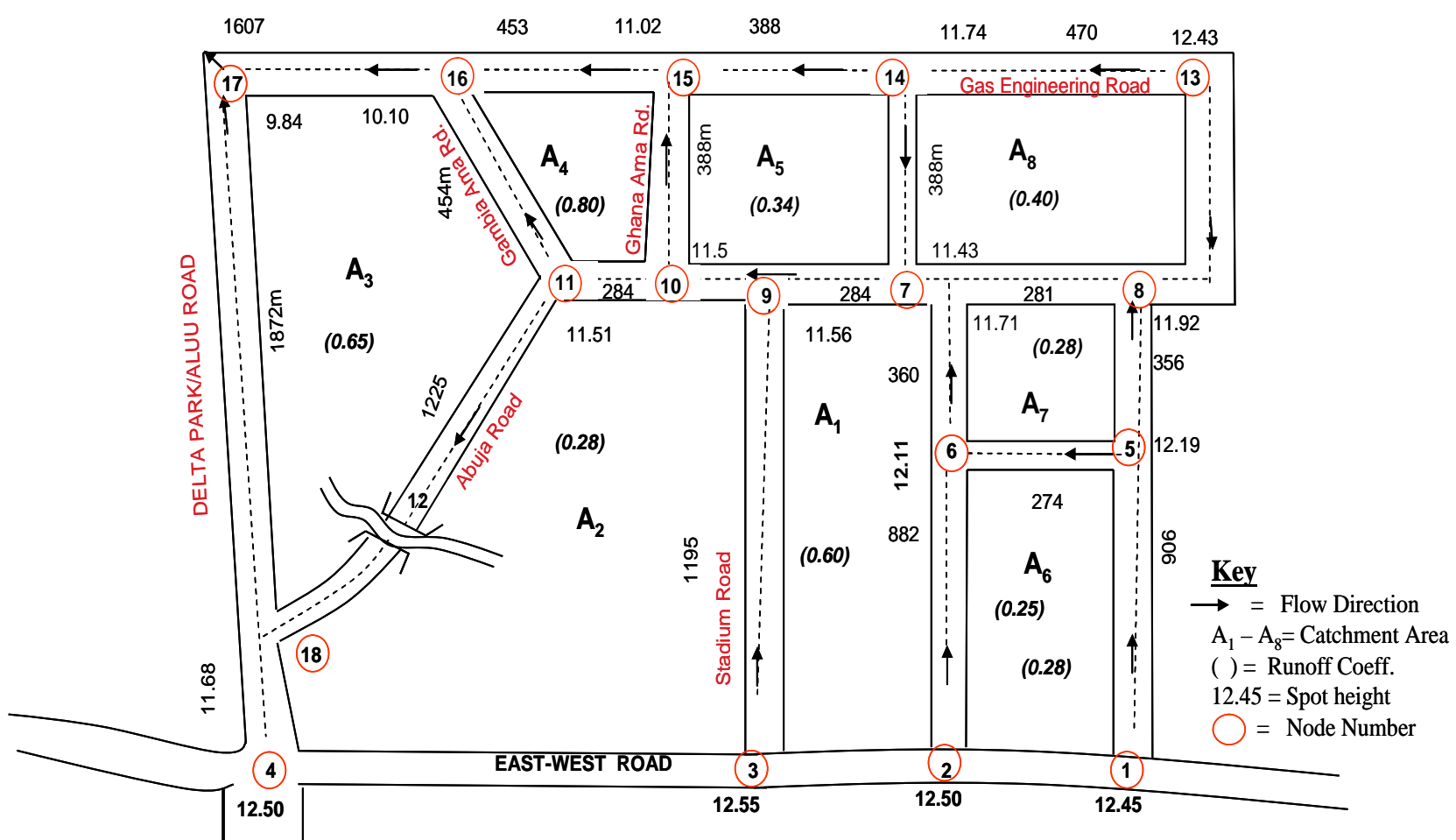

Fig. 5: Drainage Layout of University of Port Harcourt main campus (Unipark) 
Project Name: University of Port Harcourt

DRAINAGE NETWORK ANALYSIS USING RATIONAL FORMULA, RAINFALL INTENSITY VERSUS TIME OF CONCENTRATION MODEL AND BEST HYDRAULIC SECTION FOR SIZING OF DRAINS DEVELOPED BY ENGR. ITOLIMA OLOGHADIEN UNDER THE SUPERVISION OF ENGR. IFY L. NWAOGAZIE, (PhD, FNSE, FNICE) PROFESSOR OF CIVIL ENGINEERING, UNIVERSITY OF PORT HARCOURT. DRAINAGE NETWORK DESIGN FOR UNIPARK, UNIPORT

TABLE 3: INPUT DATA FOR UNIPARK NETWORK OF DRAINS

TOTAL DRAIN DESIGNATIONS $=21$

RETURN PERIOD $=6.0$ YEARS

MANNINGS COEFFICIENT $=0.013$

DRAIN SIDE SLOPE $=0.0$

\begin{tabular}{lllllll}
\hline $\mathbf{S} /$ No. & LENGTH & $\mathbf{S}_{\mathbf{o}}$ (Slope) & $\mathbf{A}_{\mathbf{c}}$ & $\mathbf{t}_{\mathbf{c}}$ & \multicolumn{1}{l}{} & Runoff \\
\hline 01 & 906.00 & 0.00029 & 11595 & 217.4772 & 0.0000521 & 0.04653 \\
02 & 1180.00 & 0.00022 & 35135 & 303.067 & 0.00000395 & 0.04716 \\
03 & 882.00 & 0.00044 & 80589 & 171.6586 & 0.00000629 & 0.24335 \\
04 & 1540.00 & 0.00111 & 77135 & 166.3778 & 0.00000644 & 0.28833 \\
05 & 1262.00 & 0.00076 & 32612 & 172.6762 & 0.00000626 & 0.15725 \\
06 & 388.00 & 0.00131 & 42015 & 52.98229 & 0.00001356 & 0.43878 \\
07 & 1543.00 & 0.00075 & 122434 & 203.0768 & 0.00000551 & 0.30352 \\
08 & 858.00 & 0.00093 & 80513 & 115.9784 & 0.00000841 & 0.52109 \\
09 & 1827.00 & 0.00053 & 1168212 & 275.1615 & 0.00000429 & 2.70411 \\
10 & 1195.00 & 0.00079 & 234262 & 162.3307 & 0.00000657 & 1.18471 \\
11 & 1977.00 & 0.00033 & 236182 & 368.1874 & 0.00000333 & 0.51157 \\
12 & 2261.00 & 0.00004 & 495978 & 1255.758 & 0.00000107 & 0.32801 \\
13 & 3486.00 & 0.00344 & 1419053 & 177.2878 & 0.00000613 & 4.52704 \\
14 & 470.00 & 0.00147 & 117161 & 57.97258 & 0.00001293 & 0.69708 \\
15 & 858.00 & 0.00186 & 163528 & 81.9209 & 0.00001058 & 0.7613 \\
16 & 2367.00 & 0.00124 & 139110 & 219.1734 & 0.00000518 & 0.47552 \\
17 & 2818.00 & 0.00203 & 174639 & 195.9172 & 0.00000567 & 0.7129 \\
18 & 2715.00 & 0.00311 & 357265 & 153.8114 & 0.00000684 & 1.8824 \\
19 & 4322.00 & 0.00016 & 872234 & 964.0193 & 0.00000137 & 0.69492 \\
20 & 278.00 & 0.00295 & 59267 & 27.313 & 0.00001808 & 0.69668 \\
21 & 1877.00 & 0.00115 & 1038946 & 190.3639 & 0.0000058 & 3.49549 \\
\hline
\end{tabular}

Where $S_{0}=$ natural slope, $A_{c}=$ catchment area, $t_{c}=$ time of concentration, $i=$ rainfall intensity.

TABLE 4: SIMULATED RESULTS ON DESIGN OF RECTANGULAR SIZED DRAINS

\begin{tabular}{|c|c|c|c|c|c|}
\hline LOCATN & DEPTH & WIDTH & VELOCITY & DRAIN CAPTY & ADJ. SLOPE \\
\hline 01 & 0.31282 & 0.57564 & 1.00376 & 0.18075 & 0.00213832 \\
\hline 02 & 0.32716 & 0.60433 & 1.01829 & 0.20133 & 0.00206754 \\
\hline 03 & 0.50074 & 0.95147 & 1.10303 & 0.52552 & 0.00134888 \\
\hline 04 & 0.45417 & 0.85833 & 1.04629 & 0.40787 & 0.00138750 \\
\hline 05 & 0.39581 & 0.74163 & 1.09951 & 0.32276 & 0.00185156 \\
\hline 06 & 0.50862 & 0.96724 & 1.22839 & 0.60432 & 0.00163750 \\
\hline 07 & 0.49375 & 0.93750 & 1.01644 & 0.47050 & 0.00116766 \\
\hline 08 & 0.57183 & 1.09366 & 1.12004 & 0.70046 & 0.00116000 \\
\hline 09 & 1.12551 & 2.20102 & 1.09156 & 2.70411 & 0.00052800 \\
\hline 10 & 0.78198 & 1.51397 & 1.00068 & 1.18471 & 0.00078900 \\
\hline
\end{tabular}




\begin{tabular}{|c|c|c|c|c|c|}
\hline LOCATN & DEPTH & WIDTH & VELOCITY & DRAIN CAPTY & ADJ. SLOPE \\
\hline 11 & 0.67803 & 1.30606 & 1.05298 & 0.93247 & 0.00081299 \\
\hline 12 & 0.86018 & 1.67035 & 1.09811 & 1.57776 & 0.00064028 \\
\hline 13 & 0.96818 & 1.88635 & 2.47878 & 4.52704 & 0.00344000 \\
\hline 14 & 0.58390 & 1.11780 & 1.06803 & 0.69708 & 0.00147000 \\
\hline 15 & 0.57802 & 1.10604 & 1.19081 & 0.76130 & 0.00186000 \\
\hline 16 & 0.52755 & 1.00510 & 1.22537 & 0.64974 & 0.00155000 \\
\hline 17 & 0.55679 & 1.06358 & 1.20382 & 0.71290 & 0.00203000 \\
\hline 18 & 0.72332 & 1.39665 & 1.86334 & 1.88240 & 0.00311000 \\
\hline 19 & 0.85638 & 1.66277 & 1.07560 & 1.53161 & 0.00061798 \\
\hline 20 & 0.51843 & 0.98686 & 1.36171 & 0.69668 & 0.00295000 \\
\hline 21 & 1.07337 & 2.09675 & 1.55314 & 3.49549 & 0.00115000 \\
\hline
\end{tabular}

NOTE THE FOLLOWING UNITS OF MEASUREMENTS:

Depth and width: metres; velocity: metre per second; discharge and drain capacity: $\mathrm{m}^{3} / \mathrm{s}$; time of concentration: minutes; rainfall intensity: $\mathrm{m} / \mathrm{s}$; length of drain: $\mathrm{m}$; catchment area: $\mathrm{m}^{2}$; fall, natural slope dimensionless.

\section{DISCUSSION OF RESULTS}

In order to establish the accuracy of MODRAIN code to model a network of drains, an attempt was made to solve an example problem (drainage design) with known solution. Thus, a network of rectangle drains shown in Fig. 3 was modeled using Modrain code and simulated results were compared and contrasted with manually computed results (Agunwamba, 2001) as shown in Table 2. Out of $13 \mathrm{No}$. drains in the network we have the following \% error distributions: $0.0-1.4 \%$ for 7 No. drains; $5.3 \%$ for 1No. drain; $11-15 \%$ for 4 No. drains; and $18.4 \%$ for 1 No. drain, respectively. The margin of error of $0.0-18.4 \%$ are mainly due to round-off error in manually computed results; which can be minimized by retaining upwards of five decimal figures in manual computations.

Similarly, a comparison of simulated drain capacities $\left(\mathrm{m}^{3} / \mathrm{s}\right)$ for the 13 No. drains were made with manually computed equivalents as shown in Fig. 4. The distribution of drain capacities (Fig. 4) by the two methods of computation are in good agreement. The slight variation is the effect of round-off error.

The MODRAIN code was subsequently applied to model the network of drains in University of Port Harcourt main campus (Unipark) as shown in Fig. 5. A total of 21 No. drains are involved. Table 3 displays both the input data set (see columns 2-4) as well as computed parameters (columns 5-7) such as time of concentration, $t_{c}$; rainfall intensity values, $i$; and corresponding runoff flow $\left(\mathrm{m}^{3} / \mathrm{s}\right), \mathrm{Q}_{\mathrm{p}}$ for each drain. The computed parameters are essentially the hydrologic aspect of the drainage design, that is, overland flow computation via the Rational formula approach (Nwaogazie and Uba, 2001).

The hydraulic aspect of the design of Unipark network of drains are as presented in Table 4. Noticeable in column 4 (Table 4) are the computed velocity values greater than 1.0 to avoid siltation and less than 3.0 to prevent erosion. The MODRAIN code has an inbuilt adjustment mechanism to update velocity values for each drain by decreasing or increasing the bottom slopes of the drains. Column 6 of Table 4 is the adjusted slope values while column 3 of Table 3 is the guessed values entered as input data. The resulting adjusted slopes are essential for drain construction for the realization of velocity values in column 4 (Table 4).

MODRAIN code has proved to be a handy tool for design of network of drains. It is possible to use MODRAIN code for design of single drain (rectangular or trapezoidal). The option for single or network of drains is achieved by indicating in the input data slot for the number of drains to be simulated. The MODRAIN code is available on request at a price.

\section{CONCLUSION}

The computer program, MODRAIN for designing of drainage system network consists of two parts: the MAIN program and a subroutine, SDRAIN. The Main program simulates catchment runoff while the subroutine SDRAIN sizes the drain by computing depth and width values of 
each channel cross-section. Results of model verification with textbook example problem showed that the model predicted the prototype network with high degree of accuracy. The margin of error as per the cross-sectional areas for the manually computed (textbook) and computer simulated solutions is between 0.0 and $18.4 \%$.

On the average, the agreement between the textbook and MODRAIN's results was very good. The field application using University of Port Harcourt main campus (Unipark) showed that the MODRAIN simulator is capable of being used to adequately simulate the process of runoff generation and sizing of drains. Thus, the MODRAIN is a reliable engineering design tool, and can be applied in the design and assessment of existing and/or proposed drainage network system.

\section{REFERENCES}

Agunwamba, J. C., 2001. Waste Engineering and Management Tools. $1^{\text {st }}$ edition, Immaculate Publications Ltd., Enugu, Nigeria.

Henderson, F. M., 1966. Open Channel Flow, Macmillian; New York, USA.

Nwaogazie, I. L and Uba, L. O., 2001. "Urban Drainage Failures and Incidence of flooding in southern Nigeria", NSE Technical Transactions, 36, (3): 45-53.

Nwaogazie, I. L and Duru, E. O., 2002. "Developing Rainfall Intensity-DurationFrequency models for Port Harcourt city", NSE Technical Transactions, 37, (2): 1932.

Nwaogazie, I. L and Nwadike, E. C., 2010. "Developing Annual and Partial serial rainfall models for Enugu city", Global J. Eng. Res., GJENR, 9, (1): and (2): 1118.

Viessman, W., John, W. K and Lewis, G. L., 2008. Introduction to Hydrology, $5^{\text {th }}$ edition. Harper and Row Publisher, Inc., New York.

Strickler, V. L and Wylie, E. B., 1981. Fluid Mechanics. $1^{\text {st }}$ metric edition, McGrawHill, Singapore. 